\title{
Correction: Thymidine phosphorylase promotes malignant progression in hepatocellular carcinoma through pentose Warburg effect
}

Qiang Zhang, Yuan Qin, Jianmin Zhao, Yuanhao Tang, Xuejiao Hu, Weilong Zhong, Mimi Li, Shumin Zong, Meng Li, Honglian Tao, Zhen Zhang, Shuang Chen, Huijuan Liu, Lan Yang, Honggang Zhou, Yanrong Liu, Tao Sun and Cheng Yang

(c) The Author(s) 2022

Cell Death and Disease (2022)13:134; https://doi.org/10.1038/s41419-022-04557-7

Correction to: Cell Death and Disease https://doi.org/10.1038/ s41419-018-1282-6, published online 17 January 2019

The original version of this article unfortunately contained a mistake in Fig. 6d. The authors pasted a wrong image from Group Twist1 + shTP (TP) for Group TP (Twist1). The coding for these two groups were similar, which made the authors paste a confused image before. This is a representative picture of immunohisto- chemistry. We examined the original data carefully. The statistical figures (Fig. 6e) showed the statistical results of the scores (average score of 4 visual fields in each section) of 4 pathological sections in each group. There is no problem with the data in the statistical figures. Although this does not affect the final conclusion, the authors apologize for the mistake. The revised figure can be found below. 
A

PLC-PRF-5

$\begin{array}{ccccc}\mathrm{Ctrl} & 0 & 0 & 0 & 0 \\ \mathrm{Tw} & & 9 & 0 & 0 \\ \mathrm{TP} & & 0 & 0 & 0 \\ \mathrm{Tw} / \mathrm{TP}(+/+) & 8 & 0 & 0 & 0 \\ \mathrm{Tw} / \mathrm{TP}(+/-) & 0 & 0 & 0 & 0\end{array}$
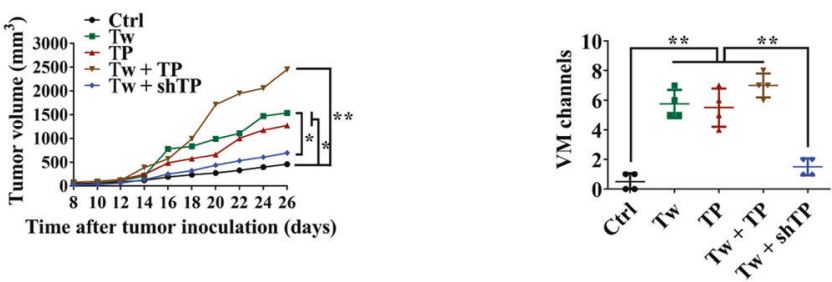

B

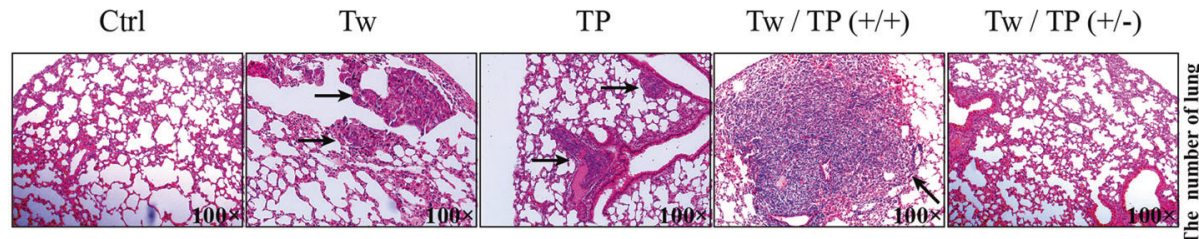

D

Ctrl

Tw

TP

$\mathrm{Tw} / \mathrm{TP}(+/+)$

$\mathrm{Tw} / \mathrm{TP}(+/-)$
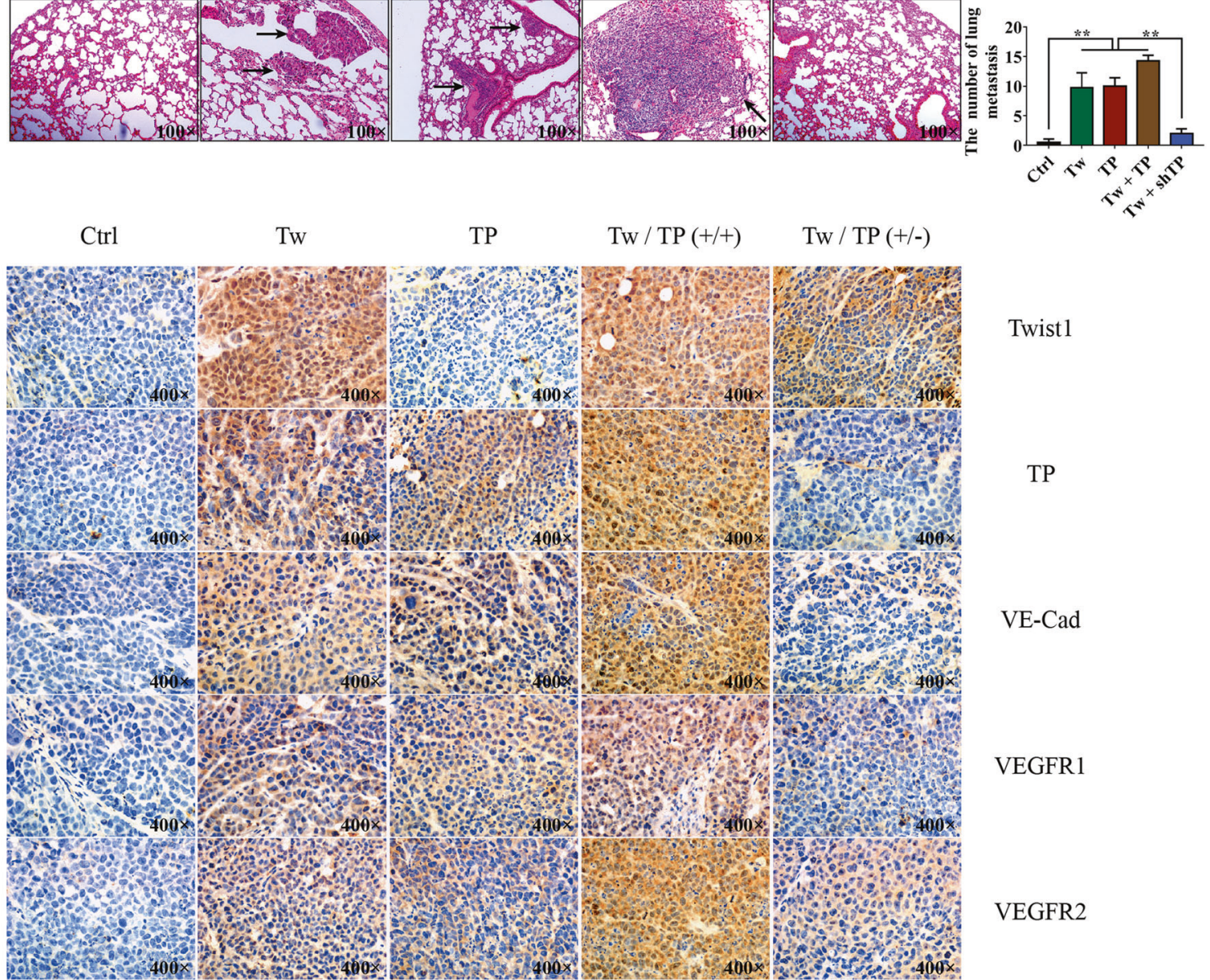

Twist1

TP

VE-Cad

VEGFR1

VEGFR2

E
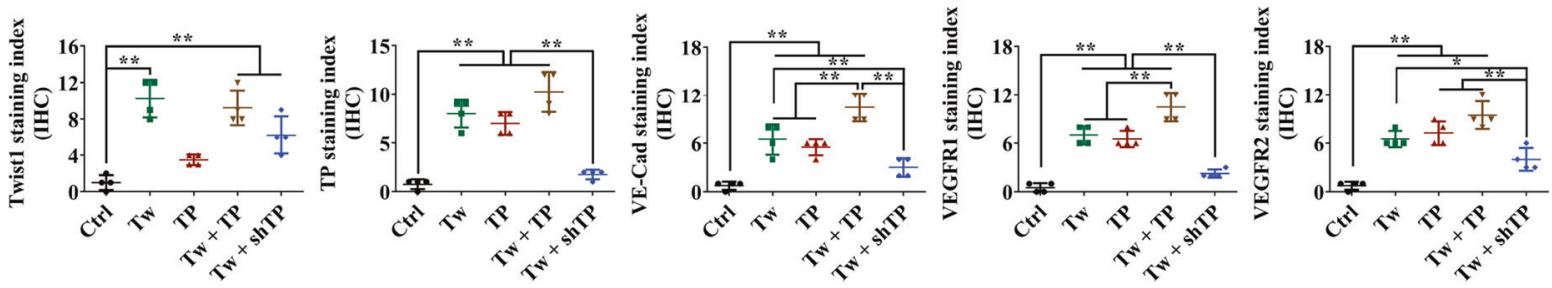
Open Access This article is licensed under a Creative Commons (c) Attribution 4.0 International License, which permits use, sharing,
adaptation, distribution and reproduction in any medium or format, as long as you give adaptation, distribution and reproduction in any medium or format, as long as you give Commons license, and indicate if changes were made. The images or other third party material in this article are included in the article's Creative Commons license, unless indicated otherwise in a credit line to the material. If material is not included in the article's Creative Commons license and your intended use is not permitted by statutory regulation or exceeds the permitted use, you will need to obtain permission directly from the copyright holder. To view a copy of this license, visit http://creativecommons. org/licenses/by/4.0/.

(c) The Author(s) 2022 